\title{
Detailed clinical assessment of neurological function in symptomatic shipyard workers
}

\author{
Martin G Cherniack, Richard Letz, Fredric Gerr, Anthony Brammer, Patricia Pace
}

\section{Abstract}

Forty eight patients with extensive occupational exposure to pneumatic grinding tools were evaluated at a university sponsored occupational health clinic. All patients were interviewed and examined by a physician and assessed neurologically with standard clinical, functional motor, quantitative vibrotactile, and electrodiagnostic tests. Sensorineural symptoms were nearly universal; 47 patients (98\%) reported numbness and tingling of the hands and fingers. Among clinical tests, two point discrimination and $30 \mathrm{~Hz}$ vibration perception were most frequently abnormal. In order to evaluate associations between quantitative test results and sensorineural symptoms, patients were stratified into two groups of symptom severity according to a consensus sensorineural staging system. The tests that discriminated best between the groups of more and less symptomatic patients were hand strength dynamometry, and vibrotactile thresholds. Age standardised $120 \mathrm{~Hz}$ vibrotactile thresholds were significantly raised in digit $\mathrm{II}$ in $41 \%$ of hand measurements. Nerve conduction studies were neither significantly different between more and less symptomatic groups nor correlated with clinical and quantitative sensory tests. Twenty five per cent of the patients had slowing of sensory conduction velocities in the median nerve at the wrist $(<48$ $\mathrm{m} / \mathrm{s})$. Of this subset of patients only two showed abnormal slowing of the median nerve distal to the wrist, but half also showed ulnar nerve slowing $(<47 \mathrm{~m} / \mathrm{s})$. This observation highlights the difficulty of differentiating median nerve entrapment from diffuse distal

Occupational Medicine Program, Yale University School of Medicine, New Haven, Connecticut, USA M G Cherniack, P Pace

Division of Environmental and Occupational Medicine, Mount Sinai School of Medicine, New York, New York, USA

R Letz, F Gerr

Division of Physics, National Research Council, Ottawa, Canada

A Brammer neuropathy in workers exposed to vibration and points to the need for concomitant quantitative sensory and functional motor assessment.

Disease of the hand and arm induced by vibration is characterised clinically by cold induced vasospasm (vibration white finger), numbness and tingling in the fingers, and more generalised dysfunction of the hands. A high prevalence of such symptoms has been reported among foundrymen and grinders in the United States, ${ }^{1}$ forestry workers in Finland, ${ }^{2-3}$ railroad mechanics in the Peoples' Republic of China ${ }^{4}$ and rock drillers in the United Kingdom. ${ }^{5}$ Although there is a consensus standard for grading of functional complaints ${ }^{6-8}$ and general recognition that the neurological disorder is confined to the distal sensory nervous system, ${ }^{9-11}$ there is no standard test or protocol that establishes a case definition. Also, the results of quantitative clinical evaluations have correlated poorly with the Taylor-Pelmear classification for vibration induced white finger. ${ }^{12}$ An additional complicating issue is a reported high prevalence of carpal tunnel syndrome ${ }^{2}$ and of diffuse polyneuropathy ${ }^{13}$ in workers with coincident use of pneumatic tools.

Most investigations of sensorineural complaints associated with vibration induced disease of the hand and arm or the hand-arm vibration syndrome, have utilised four distinct methods for assessing neurological dysfunction: (a) traditional physical assessment, (b) functional measures such as grip strength dynamometry and object recognition tests, (c) non-invasive tests of cutaneous sensory performance, and (d) electrophysiological determination of nerve conduction velocity.

Although simple and rapidly administered, the utility of clinical tests such as perception of pinprick and light touch may be compromised by interobserver variability and the forced dichotomous response of the subject. In addition, they are, by definition, insensitive to subclinical disease, and practically, tests have only given positive results in clinically advanced conditions. ${ }^{14}{ }^{15}$ Functional tests, although quantitative and rapid, have been used in only a limited manner outside the disciplines of physical therapy and rehabilitation medicine. The 
measurement of cutaneous vibrotactile perception in vibration exposed populations has been promising. ${ }^{16}$ Differences in technique, non-standard reporting of results, unclear association with symptoms, and insufficient use in studies of industrial populations, however, currently limit their utility. ${ }^{1718}$ Finally, although electrophysiological methods are considered sensitive and objective for the detection of peripheral nerve dysfunction, they have not been revealing in the study of the hand-arm vibration syndrome. A recent review of studies in which vibration exposed workers were evaluated electrophysiologically described considerable interstudy variability in technique, case selection, and determination of normal values. ${ }^{16}$ Consequently, the results of these studies have been inconsistent.

The current study is the first in a comprehensive clinical and epidemiological evaluation of a large population of shipyard workers exposed to vibration. An initial priority was to determine, in a clinically symptomatic group, how each of the four types of tests of peripheral nerve function enumerated above were related to severity of reported symptoms and stage of disease. Therefore, a consecutive series of patients with upper extremity complaints and extensive exposure to pneumatic grinding tools was examined in a standardised manner.

\section{Methods}

SUBJECTS

Fifty patients with appreciable exposure to vibration were evaluated at a university sponsored occupational medicine clinic from 1 March 1988 to 31 May 1988. All were employed in a large shipyard. At the time of evaluation 46 were either working as full time users of pneumatic grinding tools or had been recently transferred from full time grinding. The remainder reported an average use of pneumatic powered tools of four hours a day. Two subjects were excluded from the analysis because of pre-existing medical conditions known to cause neurological disease. The final study group consisted of 46 men and two women. The mean age was 44.0 (SD 13.0) years and mean duration of exposure was $15 \cdot 7$ (SD $10 \cdot 8$ ) years. Smoking histories were obtained from 47 subjects. Twenty two $(47 \%)$ reported smoking an average of 18 cigarettes a day, $21(45 \%)$ admitted to smoking in the past, and four $(9 \%)$ had never smoked. Where limbs or digits were affected by trauma or focal disease, results from tests on the affected region were excluded from the analysis but other data for the subject were retained.

\section{TESTING PROTOCOL}

\section{Symptoms}

$A$ detailed and standardised medical and occupational history was obtained by a physician.
There were specific inquiries on patterns of use of alcohol and tobacco, and on previous trauma to or disease of the upper extremity. All patients were staged clinically using the criteria of the revised Stockholm scale. ${ }^{7}$ In this system, symptoms are graded by progressive severity into four stages; the first stage being a normal presentation (0SN), stage 1 identifying intermittent numbness with or without tingling (1SN), stage II representing intermittent or persistent numbness, and reduced sensory perception $(2 \mathrm{SN})$, and stage III signifying reduced tactile discrimination and manipulative dexterity (3SN). Each hand is staged separately.

\section{Clinical tests}

A physical examination was performed by a physician to identify cervical, brachial and more distal trauma, and focal disease. A standardised clinical examination directed by a neurologist and comprising tests of pain, light touch, vibration perception extinction time to a $30 \mathrm{~Hz}$ tuning fork, and static two point discrimination was performed. Abnormal two point discrimination was defined as inability to detect a gap of $7 \mathrm{~mm}$ or more and abnormal vibration detection was defined as a perceived extinction of six seconds or less.

\section{Functional tests}

Four position hand strength dynamometry (gross grip, lateral pinch, pulp pinch, and chuck pinch) was performed using standard methods and the published normative data of Mathiowetz et al. ${ }^{19}$ Gross grip strength refers to a five finger grasp. The other positions measure strength of muscles more intrinsic to the hand. An assessment of coordination-a nonblind modified object pick up time test $\mathrm{t}^{20}$-was also performed.

\section{Vibrotactile threshold measurements}

Vibration detection thresholds were determined bilaterally at a frequency of $120 \mathrm{~Hz}$ at the distal phalanx of digit II. The Vibratron II test instrument (Sensortek Inc, Clifton, NJ) and a previously described method of limits psychophysical procedure were used to generate all thresholds. ${ }^{21}$ Thresholds were expressed as the natural logarithm of the peak to peak displacement of the stimulating surface. Observed thresholds were considered abnormal if they exceeded age specific expected values for this method by more than 1.65 standard deviations. ${ }^{22}$

\section{Electrophysiological measures}

Upper extremity nerve conduction was measured with a TECA TD-20A electromyograph (TECA Corp, Pleasantville, NY) using standard noninvasive techniques. ${ }^{23}$ Motor studies included measurement of proximal and distal latency and calculation of conduction velocity. Median nerve 
motor conduction velocity was measured by stimulating the nerve at the wrist and antecubital fossa and recording the compound motor action potential over the abductor pollicis brevis. Motor conduction velocity of the ulnar nerve was measured by stimulating the nerve at the wrist and the ulnar groove of the elbow and recording the compound motor action potential over the abductor digiti minimi. Sensory nerve conduction of the median and ulnar nerve was assessed antidromically by positioning recording electrodes bilaterally on the distal phalanxes of digits II and V. The median nerve was stimulated at the most distal wrist crease, the crease of the palm, and the medial side of the base of digit II. The ulnar nerve was stimulated at the most distal wrist crease. Stimulation artifact prevented more distal ulnar nerve stimulation. The figure shows representative tracing of distal median sensory nerve conduction from a vibration exposed patient. Median and ulnar nerve $F$ waves were measured from the wrist. Latency was measured from initiation of stimulus to the onset of the action potential. All subjects were acclimatised for 30 minutes at ambient temperature $\left(27^{\circ} \mathrm{C} \pm 0.5^{\circ} \mathrm{C}\right)$. Based on values derived locally, a lower limit of normal for sensory nerve conduction velocity was defined as $48 \mathrm{~m} / \mathrm{s}$ for median nerve values measured from wrist to finger, $47 \mathrm{~m} / \mathrm{s}$ for palm to finger, and $47 \mathrm{~m} / \mathrm{s}$ for the ulnar nerve from wrist to finger.

\section{Results}

SYMPTOMS AND CLINICAL ABNORMALITIES

In this self selected population of clinic patients the prevalence of reported symptoms was nearly universal (table 1). Forty seven (98\%) subjects reported numbness and tingling, and vasospasm was reported
Table 1 Prevalence of symptoms and abnormalities on clinical tests for entire patient group

\begin{tabular}{|c|c|}
\hline & No of patients $(\%)$ \\
\hline \multicolumn{2}{|l|}{ Symptoms: } \\
\hline & 47/48 (98) \\
\hline Loss of object control & $29 / 47(62)$ \\
\hline $\begin{array}{l}\text { Abnormal fine coordination } \\
\text { Interference with work }\end{array}$ & $\begin{array}{l}28 / 47(61) \\
40 / 47(85)\end{array}$ \\
\hline Cold independent & $33 / 47(70)$ \\
\hline Vascular symptoms & $42 / 48(88)$ \\
\hline Symptoms are seasonal & $38 / 39(97)$ \\
\hline \multicolumn{2}{|l|}{ Clinical tests:^ } \\
\hline Light touch & $11 / 44(25)$ \\
\hline Pinprick & $14 / 47(30)$ \\
\hline $30 \mathrm{~Hz}$ tuning fork & $13 / 44(30)$ \\
\hline Two point discrimination & $15 / 46(33)$ \\
\hline
\end{tabular}

by forty two ( $88 \%$ ) subjects. Most patients experien- 음 cing sensorineural symptoms also reported loss of object control $(62 \%)$, difficulty with coordination $(61 \%)$, and symptoms that interfered with work

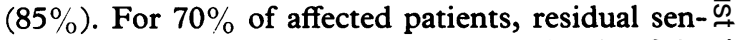
sorineural symptoms persisted independently of the $\vec{\varphi}$ cold, whereas for all but one patient, vasospastic $\circlearrowright$ attacks were only frequent or troublesome in cold weather. There was a median latency of eight years for initial neurological and vascular symptoms. Anamnestic quantification of the latent period between initial exposure and initial symptoms is $\frac{2}{\mathbb{D}}$ problematic, however, as reliability fades with longer tenure and persistence of symptoms.

Table 1 also presents the results of clinical assessment of light touch, pinprick, $30 \mathrm{~Hz}$ tuning fork extinction time, and two point discrimination. $A$ similar proportion of abnormality $(25 \%-33 \%)$ was found among these tests.

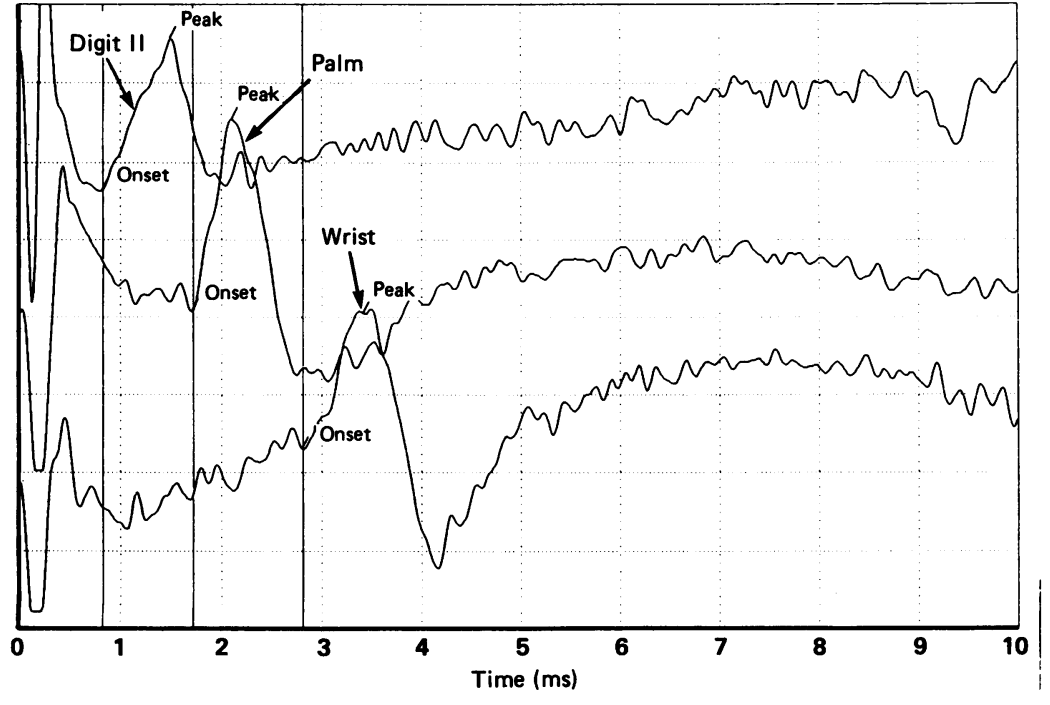

Median nerve sensory action potentials in asymptomatic patient (digit, $73.8 \mathrm{~m} / \mathrm{s} ;$ palm, $67 \cdot 5 \mathrm{~m} / \mathrm{s}$;
wrist, $66 \cdot 1 \mathrm{~m} / \mathrm{s}$ ). 
TEST RESULTS BY DISEASE STAGE

Application of the Stockholm workshop scale separately to each hand yielded 41 of 48 patients with symmetric staging - namely, the same level of disease severity. There were 20 patients $(42 \%)$ with symptoms consistent with stage I disease, $20(42 \%) 2 \mathrm{SN}$ patients, and seven $(14 \%)$ with $3 \mathrm{SN}$. One $(2 \%)$ was classified as $0 \mathrm{SN}$ bilaterally.

In order to evaluate the relations between the various quantitative test outcomes and the severity of reported sensorineural symptoms, the study population was divided into two groups according to clinical stage of disease (0-1SN and 2-3SN groups). Table 2 compares the mean values of quantitative outcomes for these two stage groups. Age and duration of exposure to vibration are included in table 2 to show that there were no significant age or exposure differences between the groups.

Two of the clinical tests yield quantitative outcomes. For two point discrimination there was a nonsignificant trend towards poorer discrimination in the more symptomatic group than in the less symptomatic group. A significant decrease in $30 \mathrm{~Hz}$ tuning fork extinction time was found bilaterally in digits II and $\mathrm{V}$ when $2-3 \mathrm{SN}$ patients were compared with $0-1 \mathrm{SN}$ patients.
Table 2 also gives the results of the five functional tests of the hand. Significantly slower object pick up times were measured in the 2-3SN group than in the $0-1 \mathrm{SN}$ group. In addition, significant reductions in all four measures of grip and pinch strength were observed bilaterally in the more symptomatic group. Similarly, vibrotactile detection thresholds were significantly higher in the more symptomatic group than in the less symptomatic group.

There were no significant differences in mean nerve conduction velocities between the two symptomatic groups for any of the nerve segments examined (table 2).

In order to evaluate the utility of the test outcomes for refinement of clinical staging, quantitative results were classified as normal or abnormal according to local reference normal values. Table 3 shows the prevalence of abnormality in the right hand stratified by clinical group. No significant differences in the proportions of abnormal findings in the two symptomatic groups were observed for any of the dichotomised clinical tests, although for the $30 \mathrm{~Hz}$ tuning fork test there was a trend toward more abnormality in the more symptomatic group.

Age specific reference values were available for dynamometry and vibrotactile threshold outcomes.

Table 2 Quantitative test results by sensorineural stage group

\begin{tabular}{|c|c|c|c|c|}
\hline & \multicolumn{2}{|l|}{ Left side } & \multicolumn{2}{|l|}{ Right side } \\
\hline & $\begin{array}{l}0-1 S N \text { Group } \\
\text { Mean }(S D)\end{array}$ & $\begin{array}{l}2-3 S N \text { Group } \\
\text { Mean (SD) }\end{array}$ & $\begin{array}{l}0-1 S N \text { Group } \\
\operatorname{Mean}(S D)\end{array}$ & $\begin{array}{l}2-3 S N \text { Group } \\
\text { Mean (SD) }\end{array}$ \\
\hline $\begin{array}{l}\text { Demographics: } \\
\text { Number } \\
\text { Age (y) } \\
\text { Exposure (y) } \\
\text { Smoking (packs a day) }\end{array}$ & $\begin{array}{l}23 \\
42 \cdot 5(14 \cdot 1) \\
16 \cdot 4(10 \cdot 3) \\
0 \cdot 8(0 \cdot 3)\end{array}$ & $\begin{array}{l}25 \\
45 \cdot 4(12 \cdot 1) \\
15 \cdot 1(11 \cdot 7) \\
1 \cdot 2(0 \cdot 4)^{\star}\end{array}$ & $\begin{array}{l}21 \\
42.0(13.7) \\
16.7(10 \cdot 7) \\
0.8(0.4)\end{array}$ & $\begin{array}{l}27 \\
45 \cdot 6(12.5) \\
15 \cdot 0(11 \cdot 3) \\
1.2(0.4)^{\star}\end{array}$ \\
\hline $\begin{array}{l}\text { Clinical tests: } \\
\text { Two point digit II (mm) } \\
\text { Two point digit V (mm) } \\
30 \mathrm{~Hz} \text { tuning fork II (s) } \\
30 \mathrm{~Hz} \text { tuning fork V (s) }\end{array}$ & $\begin{array}{l}5 \cdot 4(1 \cdot 1) \\
5 \cdot 7(1 \cdot 1) \\
9 \cdot 9(3 \cdot 4) \\
9 \cdot 5(2 \cdot 7)\end{array}$ & $\begin{array}{l}6 \cdot 4(2 \cdot 8) \\
6 \cdot 8(2 \cdot 9) \\
6 \cdot 8(3 \cdot 1)^{\star \star} \\
7 \cdot 4(3 \cdot 5)^{\star}\end{array}$ & $\begin{array}{r}5 \cdot 7(1 \cdot 3) \\
5 \cdot 7(0 \cdot 8) \\
9 \cdot 5(3 \cdot 9) \\
10 \cdot 0(3 \cdot 4)\end{array}$ & $\begin{array}{l}6 \cdot 7(2 \cdot 7) \\
6 \cdot 4(2 \cdot 4) \\
6 \cdot 8(2 \cdot 7)^{\star} \\
7 \cdot 8(3 \cdot 6)^{\star}\end{array}$ \\
\hline $\begin{array}{l}\text { Functional tests: } \\
\text { Object pickup time (s) } \\
\text { Hand dynamometry (kg) } †\end{array}$ & $11 \cdot 7(2 \cdot 7)$ & $15 \cdot 8(8 \cdot 0)^{\star}$ & $11 \cdot 7(3 \cdot 4)$ & $16.0(6.4)^{\star \star}$ \\
\hline $\begin{array}{l}\text { Gross grip } \\
\text { Lateral pinch } \\
\text { Pulp pinch } \\
\text { Chuck pinch }\end{array}$ & $\begin{array}{r}34 \cdot 7(9 \cdot 2) \\
9 \cdot 3(2 \cdot 0) \\
8 \cdot 4(1 \cdot 7) \\
9 \cdot 1(2 \cdot 3)\end{array}$ & $\begin{array}{c}24 \cdot 6(16 \cdot 1)^{\star} \\
7 \cdot 4(2 \cdot 5)^{\star \star} \\
5 \cdot 9(2 \cdot 7)^{\star \star \star} \\
6 \cdot 6(2 \cdot 8)^{\star \star}\end{array}$ & $\begin{array}{c}38 \cdot 1(11 \cdot 8) \\
9 \cdot 8(1 \cdot 4) \\
8 \cdot 3(1 \cdot 8) \\
9.4(2 \cdot 0)\end{array}$ & $\begin{array}{l}25 \cdot 4(15 \cdot 1)^{\star \star} \\
7 \cdot 6(2 \cdot 4)^{\star \star \star} \\
5 \cdot 9(2 \cdot 3)^{\star \star \star} \\
6 \cdot 7(2 \cdot 4)^{\star \star \star}\end{array}$ \\
\hline $\begin{array}{l}\text { Vibrotactile thresholds: } \\
\text { Digit II }(\log \mu \mathrm{m})\end{array}$ & $1.32(0.9)$ & $2 \cdot 10(1 \cdot 1)^{\star \star}$ & $1.02(0.9)$ & $1.98(1 \cdot 1)^{\star \star}$ \\
\hline $\begin{array}{l}\text { Nerve conduction velocity: } \\
\text { Median motor }(\mathrm{m} / \mathrm{s}) \\
\text { Median sensory WF } \ddagger(\mathrm{m} / \mathrm{s}) \\
\text { Median sensory PF } \ddagger(\mathrm{m} / \mathrm{s}) \\
\text { Median sensory FF } \ddagger(\mathrm{m} / \mathrm{s}) \\
\text { Median F wave }(\mathrm{ms}) \\
\text { Ulnar motor }(\mathrm{m} / \mathrm{s}) \\
\text { Ulnar sensory WF } ¥(\mathrm{~m} / \mathrm{s}) \\
\text { Ulnar F wave }(\mathrm{ms})\end{array}$ & $\begin{array}{l}53 \cdot 7(7 \cdot 5) \\
52 \cdot 7(10 \cdot 7) \\
57 \cdot 4(8 \cdot 7) \\
56 \cdot 4(12 \cdot 7) \\
25 \cdot 1(1 \cdot 6) \\
55 \cdot 5(6 \cdot 1) \\
54 \cdot 8(7 \cdot 0) \\
26 \cdot 3(1 \cdot 5)\end{array}$ & $\begin{array}{l}53 \cdot 0(4 \cdot 1) \\
51 \cdot 0(7 \cdot 8) \\
58 \cdot 8(6 \cdot 8) \\
60 \cdot 7(10 \cdot 2) \\
25 \cdot 7(2 \cdot 2) \\
54 \cdot 2(5 \cdot 0) \\
55 \cdot 2(6 \cdot 8) \\
26 \cdot 8(2 \cdot 3)\end{array}$ & $\begin{array}{l}53.9(5 \cdot 6) \\
52.8(9.3) \\
57.8(8 \cdot 0) \\
52.6(8.8) \\
25.2(1.3) \\
57 \cdot 2(6 \cdot 1) \\
53.4(7.4) \\
26.5(1.9)\end{array}$ & $\begin{array}{l}55 \cdot 1(4 \cdot 8) \\
51 \cdot 8(7 \cdot 7) \\
60 \cdot 5(7 \cdot 1) \\
58 \cdot 5(11 \cdot 6) \\
25 \cdot 7(2 \cdot 3) \\
56 \cdot 9(4 \cdot 3) \\
54 \cdot 7(7 \cdot 8) \\
26 \cdot 9(2 \cdot 3)\end{array}$ \\
\hline
\end{tabular}

${ }^{\star} t$ Test for difference between symptom groups $\mathrm{p}<0.05 ;{ }^{\star \star} \mathrm{p}<0.01 ;{ }^{\star \star \star} \mathrm{p}<0.001$.

tDynamometry reported for men only (two women excluded).

$\ddagger W F=$ wrist to finger; $P F=$ palm to finger; $F F=$ finger to finger. 
Table 3 Prevalence of abnormalities on various tests by sensorineural stage group

\begin{tabular}{|c|c|c|c|}
\hline & \multicolumn{2}{|c|}{ No of subjects } & \multirow[b]{2}{*}{ p Value } \\
\hline & $\begin{array}{l}0-1 S N \\
\text { Group }\end{array}$ & $\begin{array}{l}2-3 S N \\
\text { Group }\end{array}$ & \\
\hline $\begin{array}{l}\text { Clinical tests (digit II): } \\
\text { Light touch } \\
\text { Pinprick } \\
\text { Two point discrimination } \\
30 \mathrm{~Hz} \text { tuning fork }\end{array}$ & $\begin{array}{r}7 / 19 \\
10 / 21 \\
6 / 19 \\
3 / 20\end{array}$ & $\begin{array}{r}9 / 26 \\
11 / 25 \\
9 / 25 \\
10 / 24\end{array}$ & $\begin{array}{l}\text { NS } \\
\text { NS } \\
\text { NS } \\
\text { NS }\end{array}$ \\
\hline $\begin{array}{l}\text { Functional tests: } \\
\text { Hand dynamometry: } \\
\text { Gross grip } \\
\text { Lateral pinch } \\
\text { Pulp pinch } \\
\text { Chuck pinch }\end{array}$ & $\begin{array}{l}4 / 20 \\
1 / 20 \\
1 / 20 \\
1 / 19\end{array}$ & $\begin{array}{r}16 / 26 \\
14 / 26 \\
9 / 26 \\
15 / 26\end{array}$ & $\begin{array}{l}0.007 \\
0.0005 \\
0.03 \\
0.0004\end{array}$ \\
\hline $\begin{array}{l}\text { Vibrotactile thresholds: } \\
\text { Digit II }\end{array}$ & $2 / 20$ & $14 / 27$ & 0.004 \\
\hline $\begin{array}{l}\text { Nerve conduction velocity: } \\
\text { Median sensory WF }{ }^{\dagger} \\
\text { Median sensory PF }{ }^{\dagger} \\
\text { Ulnar sensory WF } \dagger\end{array}$ & $\begin{array}{l}4 / 19 \\
2 / 19 \\
3 / 18\end{array}$ & $\begin{array}{l}7 / 25 \\
0 / 25 \\
6 / 24\end{array}$ & $\begin{array}{l}\text { NS } \\
\text { NS } \\
\text { NS }\end{array}$ \\
\hline
\end{tabular}

$\star$ Fisher's exact test (two tailed).

$N S=$ not significant $(p>0.05)$.

$+\mathrm{WF}=$ wrist to finger; $\mathrm{PF}=$ palm to finger

As in the quantitative results, dichotomised outcomes for these tests discriminated significantly between the $0-1 S N$ and $2-3 S N$ stage groups. Five to $20 \%$ of the $0-1 \mathrm{SN}$ group were abnormal in these tests, whereas 34 to $62 \%$ of the $2-3 S N$ group were abnormal, depending on the test and the site tested (table 2). Similar results were found for the left hand (not shown). When the results for both hands were combined, 39 of 94 vibrotactile thresholds for digit II were more than 1.65 standard deviations above age specific expected values. For 15 patients vibrotactile measurements were also made on the pad of digit $\mathrm{V}$. Five of these were abnormal and in all five instances the digit II thresholds were similarly abnormal.

Seventeen to $25 \%$ of the median and ulnar nerve conduction velocities measured from wrist to finger were abnormal. In addition, more abnormal nerve conduction velocities were seen in the $2-3 S N$ group than in the $0-1 S N$ group. The proportions of abnormal findings were not significantly different, however, between the two symptom stage groups for any of the nerve conduction measures.

\section{ADDITIONAL NERVE CONDUCTION ANALYSES}

Patients were grouped according to whether they had abnormal sensory median nerve conduction velocities from wrist to finger. Eleven patients had abnormally slowed conductions in this segment. All 11 had symptoms and clinical findings (for example, positive Tinel's test) consistent with the diagnosis of the carpal tunnel sydrome. In over half the patients with sensory conduction abnormalities of the median nerve in the wrist finger segment, the traditional site of distal conduction measurement, slowing was accompanied by abnormal conduction in the ulnar nerve $(<47 \mathrm{~m} / \mathrm{s})$.

To test the specific hypothesis that there was? isolated slowing in the median nerve, sensory con- $\frac{\bar{F}}{\overline{0}}$ duction velocities for the median nerve were regres- $\frac{5}{3}$ sed (separately for each segment) upon the sensory 0 conduction velocity of the ulnar nerve from the same is hand. The conduction velocity of the ulnar nerve was $\vec{\circ}$ used to control for generalised effects on nerve conduction including age, polyneuropathy, varia- $\vec{\omega}$ tions in skin temperature, and even an indiscriminate effect of vibration exposure to the entire hand. Work $\frac{\mathbb{D}}{7}$ tenure was also included in the regression models. As shown in table 4, conduction velocity of the ulnar. nerve was highly significantly related to all of the sensory velocities of the median nerve. Work tenure 8 was significantly related bilaterally to sensory con-o duction velocity of the median nerve in the wrist finger segment, but not in the palm finger or finger finger segments. In an attempt to determine whether the observed slowing of the median nerve at the wrist $\frac{}{\omega}$ was related to symptoms, a variable indicating membership in the $2-3 S N$ group was substituted for the 8 work tenure variable in the regression models. No. significant relation was found between the symptom group variable and sensory conduction velocity in any median nerve segment when sensory velocity of the ulnar nerve was used as a covariate.

\section{Discussion}

Four principal testing approaches-clinical, functional, quantitative sensory, and electrophysiological-were pursued in a group of patients referred for revaluation of hand-arm vibration syn- $\stackrel{\circ}{\circ}$ drome. Patients were studied because the hand-arm $?$ vibration syndrome represents a clinically broad and physiologically poorly understood entity, and associations between outcomes would be further $\delta$ diluted by measuring effects in a symptomatically variegate population. On the other hand, data from 을 affected patients cannot avoid self selection, which

Table 4 Results of regressing segmental median sensory nerve conduction velocities on the ipsilateral ulnar sensory conduction velocities

\begin{tabular}{|c|c|c|}
\hline \multirow[b]{2}{*}{ Median nerve site $†$} & \multicolumn{2}{|c|}{ Regression coefficient (probability ${ }^{\star}$ ) } \\
\hline & $\begin{array}{l}\text { Ulnar conduction } \\
\text { velocity }\end{array}$ & Work tenure \\
\hline $\begin{array}{l}\text { Left wrist } \\
\text { Left palm } \\
\text { Left finger } \\
\text { Right wrist } \\
\text { Right palm } \\
\text { Right finger }\end{array}$ & $\begin{array}{l}0.64(0.0011) \\
0.75(0.0001) \\
0.74(0.0016) \\
0.59(0.0001) \\
0.66(0.0001) \\
0.82(0.0002)\end{array}$ & $\begin{array}{l}-0.27(0.02) \\
-0.05(0.59) \\
-0.23(0.09) \\
-0.24(0.01) \\
-0.04(0.69) \\
-0.09(0.49)\end{array}$ \\
\hline
\end{tabular}

* Probability associated with $t$ test that estimated regression $\underset{\gamma}{\sigma}$ coefficient $=0$.

+ The sites of stimulation are listed. The recording site was the distal portion of the corresponding finger. 
holds certain disadvantages for the interpretation of clinical and psychophysical tests that have a voluntary component. By comparing groups of more symptomatic and less symptomatic patients, however, the role for selection in biasing conclusions was minimised. In addition, the consistency of results between tests with very different testing strategies suggests that variation in effort contributed little to the observations in the present study.

The absence in this clinical series of concurrent observations on an unexposed control population requires a cautionary approach to inferences about the prevalence of abnormality. In this study prevalence of abnormality was used only in a relative sense, in comparisons between more symptomatic and less symptomatic groups and the same criteria for abnormality were applied equally to both groups. Nevertheless, for those tests having well established normal values-for example, vibrotactile thresholds ${ }^{22}$-abnormality was seen in a substantial proportion of the patients.

Associations between the four principal testing approaches and clinical staging were pursued in order to assess preferred methods for objective quantification of severity of disease and to localise the neurological abnormality. In this context, there are four salient points of discussion: (1) the inconsistency of associations between objective tests and clinical staging; (2) the role of mechanoreceptor injury; (3) the quantification of early $v$ late effects; and (4) the role of nerve entrapment injury.

As noted, poor correlation between the TaylorPelmear clinical staging system and objective test findings has been described. ${ }^{12}$ In the present study, classification of disease according to the Stockholm workshop scale was significantly related to quantifiable sensory and functional outcomes. Vibrotactile thresholds and measures of grip strength were significantly raised in those patients with more advanced sensorineural symptoms. Nerve conduction studies did not, however, differentiate between the two symptom groups. In addition, measures of hand strength and vibrotactile thresholds were the most deviant quantitative measurements between exposed workers and local reference populations. These findings confirm other reports of raised vibrotactile threshold ${ }^{2}$ and diminished grip strength $^{24-26}$ in vibration exposed workers. Three tests-two point discrimination, $30 \mathrm{~Hz}$ vibration recognition, and $120 \mathrm{~Hz}$ vibrotactile thresholdsdiscriminated between symptom groups and were significantly correlated with one another in this patient group. They should be considered as candidates for inclusion in studies of less severely affected groups because they are simple, can be quantified, and can be administered to a specific site of potential injury.
Although it is sometimes presumed that perceptual deficits seen in workers exposed to vibration represent injury to neuroreceptors in the fingertips, ${ }^{18}$ specific anatomical correlations are probably premature. Spatial resolution and low frequency vibration detection seem to involve a single receptor, the SAI type, ${ }^{27} 28$ and vibration induced dysfunction of this receptor system has been observed. ${ }^{17}$ There is also support for the contention that a raised vibrotactile threshold in the $100-128 \mathrm{~Hz}$ range, presumably reflecting injury to the FAII mechanoreceptor or pacinian corpuscle, is a particularly sensitive measure of injury in vibration exposed subjects, becoming abnormal before deficits are recognised on clinical or electrodiagnostic tests. ${ }^{1729}$ In the present group of highly symptomatic patients, $30 \mathrm{~Hz}$ tuning fork extinction, two point discrimination, and $120 \mathrm{~Hz}$ vibrotactile thresholds were significantly intercorrelated, and none was correlated significantly with nerve conduction velocities. Comparisons between the two symptom groups showed that vibrotactile thresholds at $120 \mathrm{~Hz}$ discriminated best, whereas $30 \mathrm{~Hz}$ tuning fork extinction times were less discriminatory and two point thresholds showed only non-significant trends toward differences. These tests did not, however, use psychophysically equivalent methods and their sensitivities may not have been equivalent. Future studies should include measurement of vibrotactile thresholds at multiple frequencies with consistent methodologies. Also, as the current study was a cross sectional one of symptomatic patients, it is not possible to confirm that these are early measures of disease or that they predict clinical course. A longitudinal study would be needed to address this central issue.

Conduction velocities in median and ulnar sensory nerves were reduced among $20-25 \%$ of the cases. There was evidence for focal block of the median nerve at the wrist as well as slowing in the more distal segments of the median nerve and the ulnar nerve. Independent of their value in an individual case, however, nerve conduction studies did not quantify abnormality in this clinical population in a manner that corresponded to severity of symptoms.

Our results do not support the contentions made by others that persistent neuritic complaints in workers exposed to vibration are the symptomatic concomitant of focal nerve entrapment ${ }^{30}$ Slowing of distal median nerve conduction across the wrist was as pronounced in a quarter of the cases in the present series, a result consistent with other observations in workers exposed to vibration. ${ }^{2}$ The presence of nerve conduction slowing and sensory loss in the ulnar nerve distribution, however, complicate the picture and suggest concomitant vibration induced damage unrelated to the carpal tunnel syndrome.

Given that there is an apparent acceleration of the diagnosis of industrially related carpal tunnel syn- 
drome, ${ }^{31} 32$ at least in the United States, that diagnostic criteria are inconsistently applied, ${ }^{33}$ and that clinical tests are poorly predictive, ${ }^{34}$ these results raise a number of questions. One concerns the discordance between typical symptoms and atypical electrophysiological findings; another, the established criteria for surgical intervention. In any event, there seems little virtue in stressing an exclusive differentiation between vibration induced neuropathy and non-vibration induced entrapment neuropathy unless clearly unifocal findings and therapeutic urgency require the distinction.

In conclusion, in this clinical population of symptomatic shipyard workers, sensorineural complaints were ubiquitous. By personal retrospective assessment, symptoms started after the onset of use of pneumatic tools in all cases, establishing a presumptive relation to employment. Confounding diagnoses were infrequent, at least in a purely recognised form. There were varied clinical and quantitative disorders that, in this limited cohort, did not encompass a single disease pattern. The most distinctive and prevalent findings were a raised vibrotactile threshold at $120 \mathrm{~Hz}$ and abnormal grip strength. These results support a role for quantitative sensory and motor testing. Close scrutiny of the pattern of test results and their correspondence with symptoms undercuts a simple approach to diagnosis and surveillance. Both a larger cohort and a longitudinal strategy would be useful in refining a quantitative case definition.

The work was supported in part by a centre grant from the US National Institute of Environmental Health Sciences to the Mount Sinai School of Medicine (ES00928-15).

Requests for reprints to: Martin G Cherniack, $M D$, MPH, Occupational Medicine Program, Yale University School of Medicine, 333 Cedar Street, New Haven, CT 06510, USA.

1 National Institute of Occupational Safety and Health. Vibration white finger disease in US workers using pneumatic chipping and grinding hand tools. I: Epidemiology. DHHS 1982; No 81:118.

2 Färkkilä M, Pyykkö I, Jantti V, Aatola S, Starck J, Korhonen O. Forestry workers exposed to vibration: a neurological study. Br J Ind Med 1988;45:188-92.

3 Pyykkö I, Korhonen O, Färkkilä M, Starck J, Aatola S. A longitudinal study of vibration syndrome among Finnish forest workers. In: Brammer AJ, Taylor W, eds. Vibration Effects on the Hand and Arm in Industry. New York: John Wiley and Sons, 1982:157-62.

4 Zeng-Shun Y, Hu C, Ling Q, De-Sheng Q, Yu-Hua Ye. Epidemiologic survey of vibration syndrome among riveters, chippers and grinders in the railroad system of the Peoples' Republic of China. Scand J Work Environ Health 1986;12:289-92.

5 Chatteriee DS, Barwick DD, Petrie A. Exploratory electromyography in the study of vibration-induced white finger in rock drillers. $\mathrm{Br} J$ Ind Med 1982;39:89-94.

6 Taylor W. Hand-arm vibration syndrome: a new clinical classification and updated British standard guide for hand-transmitted vibration. Br J Ind Med 1988;45:281-2.

7 Gemne G. Pyykkö I, Taylor W, Pelmear PL. The Stockholm workshop scale for the classification of cold-induced Raynaud's phenomenon in the hand-arm vibration syndrome (revision of the Taylor-Pelmear Scale). Scand J Work Environ Health 1987;13:275-8.
8 Brammer AJ, Taylor W, Lundborg G. Sensorineural stages of the hand-arm vibration syndrome. Scand $J$ Work Environ Health 1987;13:279-83.

9 Seppäläinen AM, Starck J, Harkonen H. High-frequency vibration and sensory nerves. Scand $J$ Work Environ Health 1986;12:420-3.

10 Färkkilä M. Clinical neurological methods in the diagnosis of the $\bar{G}$ hand-arm vibration syndrome. Scand $J$ Work Environ Health 1987;13:367-9.

11 Haines T, Chong JP. Peripheral neurological assessment methods for workers exposed to hand-arm vibration. Scand JWork Environ Health 1987;13:370-4.

12 Taylor W, Ogston SA, Brammer AJ. A clinical assessment of seventy-eight cases of the hand-arm vibration syndrome. Scand J Work Environ Health 1986;12:265-8.

13 Juntunen J, Matikainen E, Seppäläinen A-M, Laine A. Peri- O pheral neuropathy and vibration syndrome. Int Arch Occup Environ Health 1983;52:17-24.

14 Dellon AL. Clinical use of vibratory stimuli to evaluate peripheral nerve injury and compression neuropathy. Plast $\doteq$ Reconstr Surg 1980;65:466-76.

15 Szabo RM, Gelberman GH, Dimick MP. Sensibility testing of patients with carpal tunnel syndrome. J Bone Joint Surg [Am] G 1984;66:60-4.

16 Brammer AJ, Pyykkö I. Vibration-induced neuropathy: detec- $O$ tion by nerve conduction measurements. Scand $J$ Work Environ Health 1987;13:317-22.

17 Brammer AJ, Piercy JE, Auger PL, Nohara S. Tactile percep- I tion in hands occupationally exposed to vibration. $J$ Hand Surg $A m] 1987 ; 12: 870-5$.

18 Lundborg G, Lie-Stenstrom A-K, Sollerman C, Stromberg T, Pyykkö I. Digital vibrogram: a new diagnostic tool for sensory testing in compression neuropathy. $J$ Hand Surg $[\mathrm{Am}]$ 1986;11:693-9.

19 Mathiowetz V, Kashman N, Volland G, Weber K, Dowe M, Rogers S. Grip and pinch strength: normative data for adults. Arch Phys Med Rehabil 1985;66:69-74.

20 Dellon AL. Evaluation of sensibility and re-education of sensation in the hand. Baltimore: The Williams and Wilkins Co, 1981

21 Gerr FE, Letz R. Reliability of a widely used test of peripheral cutaneous vibration sensitivity and a comparison of two testing protocols. $\mathrm{Br} J$ Ind Med 1988;45:635-9.

22 Gerr FE, Hershman D, Letz R. Vibrotactile threshold $\overrightarrow{\vec{O}}$ measurement for detecting neurotoxicity: reliability and determination of age- and height-standardized normative values. Arch Environ Med (in press).

23 Chu-Andrews A, Johnson RJ. Electrodiagnosis: an anatomical and clinical approach. Philadelphia: JB Lippincott, 1986: 290-308.

24 Färkkilä $M$. Grip force in vibration disease. Scand $J$ Work Environ Health 1978;4:159-66.

25 Färkkilä M, Pyykkö I, Korhonen O, Starck J. Hand grip forces during chain saw operation and vibration-induced white finger in lumberjacks. $\mathrm{Br} J$ Ind Med 1979;36:336-41.

26 Färkkilä M, Aatola S, Starck J, Korhonen O, Pyykkö I. Hand O grip force in lumberjacks: two-year follow-up. Int Arch Occup Environ Health 1986;58:203-8.

27 Mountcastle VB, Lamothe RH, Carli G. Detection thresholds for stimuli in humans and monkeys: Comparison with thres- $I$ hold events in mechanoreceptor afferent fibres innervating the monkey hand. $J$ Neurophysiol 1972;35:122-36.

28 Johnson KO, Phillips JR. Tactile spatial resolution. I: Two- $N$ point discrimination, gap detection, grating resolution, and $S$ letter recognition. $J$ Neurophysiol 1981;46:1177-91.

29 Szabo RM, Gelberman GH, Williamson RV, Dellon AL, York $\mathrm{O}$ NL, Dimick MP. Vibratory sensory testing in acute peripheral N nerve compression. J Hand Surg $[$ Am $]$ 1985;9:104-8.

30 Juntunen J, Taskinen $H$. Pathogenic and clinical aspects of $\underset{<}{\sigma}$ polyneuropathies, with reference to the hand-arm vibration $\bullet$ syndrome. Scand J Work Environ Health 1987;13:363-6.

31 Masear VR, Hayes JM, Hyde AG. An industrial cause of carpal $\mathscr{D}$ tunnel syndrome. J Hand Surg $[$ Am $]$ 1986;11:222-7.

32 Katz JN, Liang MH. Carpal tunnel syndrome and the workplace: epidemiologic and management issues. Intern Med 1988;9:66-73.

33 Dowart BB. Carpal tunnel syndrome: a review. Semin Arthritis Rheum 1984;14:134-40.

34 Spindler HA, Dellon AL. Nerve conduction studies and sen- $\mathbb{Q}$ sibility testing in carpal tunnel syndrome. J Hand Surg $[\mathrm{Am}] \underset{-}{\sigma}$ $1982 ; 7: 260-3$.

Accepted 19 March 1990 . 